\title{
Steric Control in Ring-Opening Polymerization of 1,6-Anhydro Galactose Derivatives by Neighboring Group Participation
}

\author{
Kazukiyo KobaYashi,* Takahiro IsHII, Masahiko OKaDA, \\ and Conrad SCHUERCH ${ }^{\dagger}$ \\ Faculty of Agriculture, Nagoya University, Chikusa, Nagoya 464-01, Japan \\ ${ }^{\dagger}$ College of Environmental Sciences and Forestry, New York State University, \\ Syracuse, New York 13210, U.S.A.
}

(Received June 26, 1992).

\begin{abstract}
Four 1,6-anhydro- $\beta$-D-galactopyranoses having benzoyl derivatives in position 2 and benzyl derivatives in positions 3 and 4 were synthesized and polymerized. $(1 \rightarrow 6)-\beta$-DGalactopyranan oligosaccharide derivatives $\left(\overline{D P}_{n}<7.6\right)$ were obtained with $\mathrm{PF}_{5}$ as initiator in dichloromethane at 0 to $-40^{\circ} \mathrm{C}$ from 1,6-anhydro-2-O-benzoyl-3,4-di- $O$-benzyl- $\beta$-D-galactopyranose (1a), 1,6-anhydro-2-O-benzoyl-3,4-di- $O$ - $p$-bromobenzyl- $\beta$-D-galactopyranose (1c), and 1,6anhydro-2-O-p-bromobenzoyl-3,4-di-O-p-bromobenzyl- $\beta$-D-galactopyranose (1d). 1,6-Anhydro-2$O$ - $p$-nitrobenzoyl-3,4-di-O-benzyl- $\beta$-D-galactopyranose $(\mathbf{1 b})$ gave a stereoirregular product of lower molecular weight in lower yield. The apparent rate of polymerization increased in the order of $\mathbf{1 b}<\mathbf{1 a}<\mathbf{1 c}<\mathbf{1 d}$. The formation of $\beta-(1 \rightarrow 6)$-linked configuration is explained by the mechanism in which the benzoyl group in position 2 took part in the steric retention of the anomeric center during the ring-opening polymerization. Substituent effects on the reactivities of the monomers and growing species are discussed on the basis of the mechanism.
\end{abstract}

KEY WORDS Synthetic Polysaccharide / Ring-opening Polymerization / Anhydro Sugar Derivatives / Neighboring Group Participation / $(1 \rightarrow 6)-\beta$ D-Galactopyranan/

Well-defined $(1 \rightarrow 6)$ - $\beta$-linked galactopyranan is a useful model polysaccharide to study immunology and enzymology. ${ }^{1,2}$ We previously reported the synthesis of $(1 \rightarrow 6)-\beta$-Dgalacto oligosaccharides via polymerization of 1,6-anhydro-2- $O$-benzoyl-3,4-di- $O$-benzyl- $\beta$ -

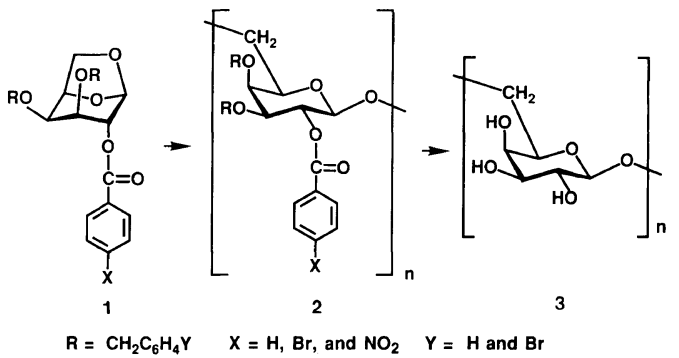

Scheme 1. Synthesis of $(1 \rightarrow 6)$ - $\beta$-D-galactopyranan $(3)$.
D-galactopyranose (1a) and subsequent deprotection according to Scheme $1 . .^{3,4}$ The formation of $\beta-(1 \rightarrow 6)$-linkage was explained by a neighboring-group effect of the benzoyl group in position 2 on the steric control of the anomeric center in the propagation step.

This paper deals with ring-opening polymerization of the four different anhydrogalactoses having benzoyl derivatives in position 2 (Figure 1): 1,6-anhydro-2- $O$-benzoyl-3,4-di- $O$-benzyl$\beta$-D-galactopyranose (1a); 1,6-anhydro-2-O-pnitrobenzoyl-3,4-di- $O$-benzyl- $\beta$-D-galactopyranose (1b); 1,6-anhydro-2-O-benzoyl3,4-di- $O$ - $p$-bromobenzyl- $\beta$-D-galactopyranose (1c); 1,6-anhydro-2- $O$ - $p$-bromobenzoyl-3,4-di- $O$ - $p$-bromobenzyl- $\beta$-D-galactopy-

* To whom correspondence should be addressed. 

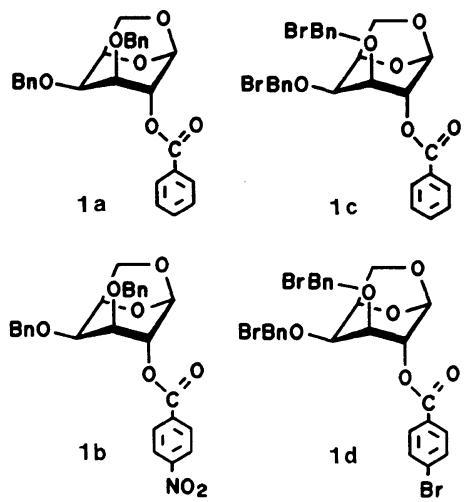

$\mathrm{Bn}, \mathrm{CH}_{2} \mathrm{O}$; $\mathrm{BnBr}, \mathrm{CH}_{2}-\mathrm{O}_{\mathrm{Br}}$

Figure 1. The structures of the monomers.

ranose (1d). Their polymerizations are investigated under several conditions and polymerization reactivities are discussed on the basis of the proposed mechanism.

\section{EXPERIMENTAL}

\section{General Methods}

$200-\mathrm{MHz}{ }^{1} \mathrm{H}$ and $50-\mathrm{MHz}{ }^{13} \mathrm{C}$ NMR spectra were obtained on a Japan Electro-Optic Laboratory JNM-FX-200 Fourier transform NMR spectrometer for solutions in deuteriochloroform and $\mathrm{Me}_{2} \mathrm{SO}-d_{6}$ with tetramethylsilane as the internal reference. For deprotected polysaccharides, measurements were made on solutions in $\mathrm{D}_{2} \mathrm{O}$ with acetone as a reference (2.07 ppm in ${ }^{1} \mathrm{H}$ NMR and $39.4 \mathrm{ppm}$ in ${ }^{13} \mathrm{C}$ NMR). Optical rotations were determined with a JASCO DIP 181 digital polarimeter using a jacketed 1-dm cell. Gel-permeation chromatography was carried out on a Toso HLC8020 high-speed chromatograph using TSKgel $\mathrm{GMH}_{\mathrm{XL}} \times 2$ and $\mathrm{G} 2000 \mathrm{H}_{\mathrm{XL}}, \mathrm{G} 3000 \mathrm{H}_{\mathrm{XL}}$, $\mathrm{G} 4000 \mathrm{H}_{\mathrm{XL}}$, and $\mathrm{G} 5000 \mathrm{H}_{\mathrm{XL}}$ columns (solvent, chloroform; polystyrene standards). Microanalysis was made on a Perkin-Elmer 240C elemental analyzer.

\section{1,6-Anhydro-2-O-benzoyl-3,4-di-O-benzyl- $\beta$-D- galactopyranose (1a) \\ It was synthesized and purified by previous-}

ly reported methods. ${ }^{5} \mathrm{mp}, 93-94^{\circ} \mathrm{C} .[\alpha]_{\mathrm{D}}^{25}=$ $+1.6^{\circ}$ (c 1.0, in chloroform). Anal. Calcd for $\mathrm{C}_{27} \mathrm{H}_{26} \mathrm{O}_{6}$ : C, $72.63 \% ; \mathrm{H}, 5.87 \%$. Found: C, $72.59 \% ; \mathrm{H}, 5.83 \%$.

${ }^{1} \mathrm{H}$ NMR $\left(\mathrm{CDCl}_{3}, \mathrm{TMS}\right): 8.07-7.28(\mathrm{~m}$, $15 \mathrm{H}$, benzoyl- and benzyl- $\left.\mathrm{C}_{6} \mathrm{H}_{5}\right), 5.53(\mathrm{~s}, 1 \mathrm{H}$, $\mathrm{H}-1), 5.22(\mathrm{~s}, 1 \mathrm{H}, \mathrm{H}-2), 4.93$ and $4.70(2 \mathrm{~d}$, $J=12.0,2 \mathrm{H}$, benzyl- $\left.\mathrm{CH}_{2}\right), 4.60-4.38(\mathrm{~m}, 4 \mathrm{H}$, $\mathrm{H}-5, \mathrm{H}-6_{\text {endo }}$, and benzyl- $\left.\mathrm{CH}_{2}\right), 3.92(\mathrm{~m}, 2 \mathrm{H}$, $\mathrm{H}-3$ and $\mathrm{H}-4)$, and $3.71(\mathrm{~d} \times \mathrm{d}, J \simeq 5.9$ and $\left.6.1 \mathrm{~Hz}, 1 \mathrm{H}, \mathrm{H}-6_{\text {exo }}\right)$.

${ }^{13} \mathrm{C}$ NMR $\left(\mathrm{CDCl}_{3}\right): 165.7(\mathrm{C}=\mathrm{O}), 138.5$ and 138.2 (ipso- $\mathrm{C}_{6} \mathrm{H}_{5}$ of benzyl), 133.8 (para$\mathrm{C}_{6} \mathrm{H}_{5}$ of benzoyl), 129.9 (ipso- $\mathrm{C}_{6} \mathrm{H}_{5}$ of benzoyl), 130.2, 128.8, 128.7, 128.2, 127.9, (other $\mathrm{C}_{6} \mathrm{H}_{5}$ of benzoyl and benzyl), $100(\mathrm{C}-1), 74.9$ (C-2), 73.6 (C-5), 73.4 (C-3), 73.1 (C-4), 71.2 and 71.1 (benzyl- $\mathrm{CH}_{2}$ ), and $62.2(\mathrm{C}-6)$.

\section{1,6-Anhydro-2-O-p-nitrobenzoyl-3,4-di-O- benzyl- $\beta$-D-galactopyranose (1b)}

It was prepared from 1,6-anhydro-3,4-di$O$-benzyl- $\beta$-D-galactopyranose. ${ }^{5} \mathrm{mp}, 107.5$ $110.5^{\circ} \mathrm{C}$. $[\alpha]_{\mathrm{D}}^{25}=+23.8^{\circ}$ (c 1.0, in chloroform). Anal. Calcd for $\mathrm{C}_{27} \mathrm{H}_{25} \mathrm{O}_{8} \mathrm{~N}: \mathrm{C}, 65.98 \% ; \mathrm{H}$, $5.13 \%$; N, 2.85\%. Found: C, 66.01\%; H, $5.16 \% ; \mathrm{N}, 2.72 \%$.

${ }^{1} \mathrm{H}$ NMR $\left(\mathrm{CDCl}_{3}, \mathrm{TMS}\right): 8.24(\mathrm{~m}, 4 \mathrm{H}$, $\left.\mathrm{C}_{6} \mathrm{H}_{4}\right), 7.35-7.25\left(\mathrm{~m}, 5 \mathrm{H}, \mathrm{C}_{6} \mathrm{H}_{5}\right), 5.53(\mathrm{~s}, 1 \mathrm{H}$, $\mathrm{H}-1), 5.21$ (s, 1H, H-2), 4.90 and $4.70(2 \mathrm{~d}$, $J=12.1,2 \mathrm{H}$, benzyl- $\left.\mathrm{CH}_{2}\right), 4.64-4.42(\mathrm{~m}, 4 \mathrm{H}$, benzyl- $\mathrm{CH}_{2}, \mathrm{H}-5$ and $\left.\mathrm{H}-6_{\text {endo }}\right), 3.91(\mathrm{~m}, 2 \mathrm{H}$, $\mathrm{H}-3$ and $\mathrm{H}-4), 3.72(\mathrm{~d} \times \mathrm{d}, J \simeq 6.2$ and $5.6 \mathrm{~Hz}$, $\left.1 \mathrm{H}, \mathrm{H}-6_{\text {exo }}\right)$.

${ }^{13} \mathrm{C}$ NMR $\left(\mathrm{CDCl}_{3}\right): 163.2(\mathrm{C}=\mathrm{O}), 150.6$ (para $-\mathrm{C}_{6} \mathrm{H}_{4}$ ), 137.7 and 137.5 (ipso- $\mathrm{C}_{6} \mathrm{H}_{5}$ ), 134.6 (ipso- $\mathrm{C}_{6} \mathrm{H}_{4}$ ), 130.8 (ortho- $\mathrm{C}_{6} \mathrm{H}_{4}$ ), 128.2 $127.4\left(\mathrm{C}_{6} \mathrm{H}_{5}\right), 123.4$ (meta- $\left.\mathrm{C}_{6} \mathrm{H}_{4}\right), 99.1(\mathrm{C}-1)$, 74.2 (C-2), 73.0 (C-5), 72.7 (C-3 and C-4), 71.5 and 70.8 (benzyl- $\left.\mathrm{CH}_{2}\right)$, and 64.7 (C-6).

\section{1,6-Anhydro-2-O-benzoyl-3,4-di-O-p-bromo- benzyl- $\beta$-D-galactopyranose (1c)}

It was prepared by treating 1,6-anhydro3,4-di- $O$ - $p$-bromobenzyl- $\beta$-D-galactopyranose with benzoyl chloride. $\mathrm{mp}, 79-81^{\circ} \mathrm{C} .[\alpha]_{\mathrm{D}}^{25}=$ 
$+12.1^{\circ}$ (c 1.0, in chloroform). Anal. Calcd for $\mathrm{C}_{27} \mathrm{H}_{24} \mathrm{O}_{6} \mathrm{Br}_{2}$ : C, 53.66\%; H, 4.00\%. Found: $\mathrm{C}, 53.67 \%$; H, 3.95\%.

${ }^{1} \mathrm{H}$ NMR $\left(\mathrm{CDCl}_{3}\right): 8.07-7.05(\mathrm{~m}, 13 \mathrm{H}$, benzoyl- $\mathrm{C}_{6} \mathrm{H}_{5}$ and $p$-bromobenzyl- $\left.\mathrm{C}_{6} \mathrm{H}_{4}\right), 5.53$ (s, 1H, H-1), 5.17 (s, 1H, H-2), 4.87 and 4.60 $\left(2 \mathrm{~d}, J=12.2,4 \mathrm{H}\right.$, benzyl- $\left.\mathrm{CH}_{2}\right), 4.55(\mathrm{~d}, J=$ 7.6, $2 \mathrm{H}, \mathrm{H}-6_{\text {endo }}$ and $\left.\mathrm{H}-5\right), 4.42(\mathrm{~d}, J=3.2$, $1 \mathrm{H}$, benzyl- $\mathrm{CH}_{2}$ ), 3.89 (broad s, $2 \mathrm{H}, \mathrm{H}-3$ and $\mathrm{H}-4)$, and $3.72(\mathrm{~d} \times \mathrm{d}, J \simeq 5.6$ and $5.4 \mathrm{~Hz}, 1 \mathrm{H}$, H- $\left.6_{\text {exo }}\right)$.

${ }^{13} \mathrm{C}$ NMR $\left(\mathrm{CDCl}_{3}\right): 165.3(\mathrm{C}=\mathrm{O}), 137.0$ and 136.6 (ipso- $\mathrm{C}_{6} \mathrm{H}_{4}$ of $p$-bromobenzyl), 133.6 (para- $\mathrm{C}_{6} \mathrm{H}_{5}$ of benzoyl), 131.5, 131.3, $129.9,129.3,129.0$, and 128.5 (ortho- and meta- $\mathrm{C}_{6} \mathrm{H}_{4}$, and ipso-, meta-, and ortho$\mathrm{C}_{6} \mathrm{H}_{5}$ ), 121.5 (para- $\mathrm{C}_{6} \mathrm{H}_{4}$ ), 99.5 (C-1), 74.3 (C-2), 72.9 (C-5), 72.8 (C-3), 71.7 (C-4), 70.3 and 69.9 ( $p$-bromobenzyl- $\left.\mathrm{CH}_{2}\right)$, and 64.6 (C-6).

\section{1,6-Anhydro-2-O-p-bromobenzoyl-3,4-O-iso-} propylidene- $\beta$-D-galactopyranose

1,6 -Anhydro- $\beta$-D-galactopyranose was prepared by a modified $\operatorname{method}^{7}$ via pentachlorophenyl 2,3,4,6-tetra- $O$-acetyl- $\beta$-D-galactopyranoside. 1,6-Anhydro-3,4- $O$-isopropylidene- $\beta$-D-galactopyranose was prepared by a modification of the reported method. ${ }^{6}$ According to Scheme 2, pentachlorophenyl $\beta$-D- galactopyranose was employed as an intermediate $^{7}$ instead of phenyl $\beta$-D-galactopyranose.

A solution of 1,6-anhydro-3,4-O-isopropylidene- $\beta$-D-galactopyranose ${ }^{6}(16.6 \mathrm{~g}, 0.082 \mathrm{~mol})$ in chloroform $(400 \mathrm{ml})$ was treated with triethylamine $(25 \mathrm{ml})$ and $p$-bromobenzoyl chloride $(50 \mathrm{~g}, 0.228 \mathrm{~mol})$ at room temperature for $6 \mathrm{~h}$. Water $(10 \mathrm{ml})$ was added and the mixture was stirred for $2 \mathrm{~h}$ and concentrated. The residue was dissolved in chloroform and washed with water and a saturated aqueous sodium hydrogen carbonate. The chloroform layer was concentrated to dryness, and the residue was crystallized from ethanol. Yield was $27 \mathrm{~g}(86 \%) \mathrm{mp}, 147.5-148.5^{\circ} \mathrm{C} .[\alpha]_{\mathrm{D}}^{25}=$ $+22.2^{\circ}$ (c, 1.0, in chloroform).

${ }^{1} \mathrm{H} \mathrm{NMR}\left(\mathrm{CDCl}_{3}\right): 7.94(\mathrm{~d}, J=8.4,2 \mathrm{H}$, ortho- $\left.\mathrm{C}_{6} \mathrm{H}_{4}\right), 7.59\left(\mathrm{~d}, \mathrm{~J}=8.4,2 \mathrm{H}\right.$, meta $\left.-\mathrm{C}_{6} \mathrm{H}_{4}\right)$, 5.49 (s, 1H, H-1), 5.12 (s, 1H, H-2), 4.59 (t, $1 \mathrm{H}, \mathrm{H}-5), 4.51$ (t, $1 \mathrm{H}, \mathrm{H}-4), 4.24$ (d, $J=6.9$, $1 \mathrm{H}, \mathrm{H}-3), 4.19$ (d, $\left.J=7.5,1 \mathrm{H}, \mathrm{H}-6_{\text {endo }}\right), 3.65$ $\left(\mathrm{d} \times \mathrm{d}, J=7.5\right.$ and $\left.5.1,1 \mathrm{H}, \mathrm{H}-6_{\text {exo }}\right)$, and 1.57 and $1.37\left(2 \mathrm{~s}, 6 \mathrm{H}, \mathrm{CH}_{3}\right)$.

${ }^{13} \mathrm{C}$ NMR $\left(\mathrm{CDCl}_{3}\right): 164.4(\mathrm{C}=\mathrm{O}), 131.8$ and 131.3 (ortho and meta $\mathrm{C}_{6} \mathrm{H}_{4}$ ), 128.6 and 128.2 (ipso and para $\mathrm{C}_{6} \mathrm{H}_{4}$ ), 109.0 (_C: $-\mathrm{OO}$ ), 98.9 (C-1), 73.9 (C-2), 72.0 (C-3 and C-5), 69.1 (C-4), 63.3 (C-6), 25.7 and $24.2\left(\mathrm{CH}_{3}\right)$.

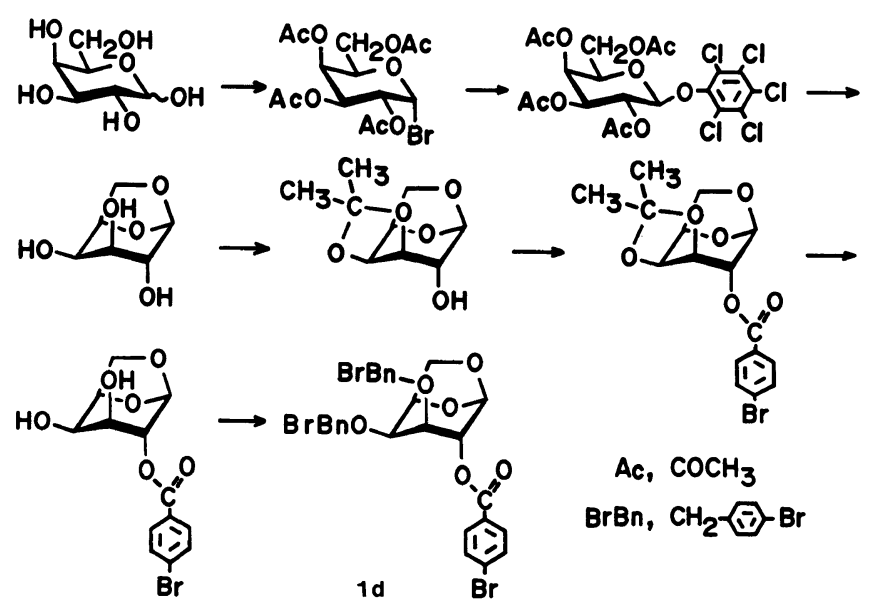

Scheme 2. Synthetic procedure of the monomer 1d. 
1,6-Anhydro-2-O-p-bromobenzoyl- $\beta$-D-galactopyranose

1,6-Anhydro-2-O-p-bromobenzoyl-3,4-Oisopropylidene- $\beta$-D-galactopyranose) $(27.3 \mathrm{~g}$, $70.7 \mathrm{mmol})$ was treated with a mixture $(250 \mathrm{ml})$ of trifluoroacetic acid and water (7:3 in volume) at room temperature for $30 \mathrm{~min}$. Methanol $(10 \mathrm{ml})$ was added and the mixture was concentrated to dryness and the residue was crystallized from ethanol. Yield was $20.6 \mathrm{~g}$ $(86 \%) .[\alpha]_{\mathrm{D}}^{25}=+56.6^{\circ}$ (c 1.0 , in dimethyl sulfoxide).

${ }^{1} \mathrm{H}$ NMR $\left(\mathrm{Me}_{2} \mathrm{SO}-d_{6}\right): 7.90(\mathrm{~d}, J=8.7,2 \mathrm{H}$, ortho $\left.-\mathrm{C}_{6} \mathrm{H}_{4}\right), 7.76\left(\mathrm{~d}, J=8.7,2 \mathrm{H}\right.$, meta $\left.-\mathrm{C}_{6} \mathrm{H}_{4}\right)$, $5.41(\mathrm{~s}, 1 \mathrm{H}, \mathrm{H}-1), 5.22$ and $5.16(\mathrm{~d}, J=3,4,1 \mathrm{H}$ and $\mathrm{d}, J=6.8,1 \mathrm{H}, \mathrm{OH}-3$ and $\mathrm{OH}-4$. These signals disappeared with a drop of $\left.\mathrm{H}_{2} \mathrm{O}\right), 4.84$ (s, 1H, H-2), 4.36 (d, H-5 and $\mathrm{H}-6_{\text {endo }}$ ), 3.85 (broad s, 2H, H-3 and H-4), and 3.50 (broad $\left.\mathrm{d} \times \mathrm{d}, 1 \mathrm{H}, \mathrm{H}-6_{\text {exo }}\right)$.

${ }^{13} \mathrm{C} \mathrm{NMR}\left(\mathrm{Me}_{2} \mathrm{SO}-d_{6}\right): 163.8(\mathrm{C}=\mathrm{O}), 131.8$ and 131.2 (ortho- and meta- $\mathrm{C}_{6} \mathrm{H}_{4}$ ), 128.3 (ipso- $\mathrm{C}_{6} \mathrm{H}_{4}$ ), 127.5 (para- $\left.\mathrm{C}_{6} \mathrm{H}_{4}\right), 98.1(\mathrm{C}-1)$, 74.0 (C-2), 73.7 (C-5), 67.9 (C-3), 64.6 (C-4), and 63.1 (C-6).

\section{p-Bromobenzyl Trichloroacetimidate}

The method ${ }^{8,9}$ reported for benzyl trichloroacetimidate was modified. Sodium hydride (110 mg, $2.7 \mathrm{mmol})$ was washed with hexane and dispersed in tetrahydrofuran $(3 \mathrm{ml}) . p$ Bromobenzyl alcohol $(5.0 \mathrm{~g}, 27 \mathrm{mmol})$ in tetrahydrofuran $(5 \mathrm{ml})$ was added to it in an atmosphere of nitrogen. The mixture was cooled at $0^{\circ} \mathrm{C}$ in an ice bath. Trichloroacetonitrile $(2.7 \mathrm{ml}, 26.7 \mathrm{mmol})$ was added through a dropping funnel for $15 \mathrm{~min}$. The mixture was gradually warmed to room temperature over a period of $60 \mathrm{~min}$ and concentrated. Crude crystals deposited were dissolved into $n$-hexane containing a small amount of methanol. The supernatant was decanted and concentrated. Yield was $8.6 \mathrm{~g}(97 \%)$. The colorless crystal was stored in a refrigerator.

${ }^{1} \mathrm{H}$ NMR (7.1\% in $\mathrm{CDCl}_{3}$, TMS, $\left.200 \mathrm{MHz}\right)$ : $\delta 8.41(\mathrm{~s}, 1 \mathrm{H}, \mathrm{NH}), 7.50(\mathrm{~d}, J=8.6,2 \mathrm{H}$, meta- $\left.\mathrm{C}_{6} \mathrm{H}_{4}\right), 7.30\left(\mathrm{~d}, J=8.6,2 \mathrm{H}\right.$, ortho $\left.-\mathrm{C}_{6} \mathrm{H}_{4}\right)$, and $5.28\left(\mathrm{~s}, 2 \mathrm{H}, \mathrm{CH}_{2}\right)$.

$\left.{ }^{13} \mathrm{C} \mathrm{NMR} \mathrm{(7.1 \%} \mathrm{in} \mathrm{CDCl}_{3}, \mathrm{TMS}, 50 \mathrm{MHz}\right)$ : $162.1(\mathrm{C}=\mathrm{NH}), \quad 134.2 \quad$ (ipso- $\left.\mathrm{C}_{6} \mathrm{H}_{4}\right), 131.4$ (meta- $\mathrm{C}_{6} \mathrm{H}_{4}$ ), 129.1 (ortho- $\mathrm{C}_{6} \mathrm{H}_{4}$ ), 122.1 (para$\left.\mathrm{C}_{6} \mathrm{H}_{4}\right)$, and $69.7\left(\mathrm{CH}_{2}\right)$.

\section{1,6-Anhydro-2-O-p-bromobenzoyl-3,4-di-O-p- bromobenzyl- $\beta$-D-galactopyranose (1d)}

1,6-Anhydro-2- $O$ - $p$-bromobenzoyl- $\beta$-Dgalactopyranose $(1.1 \mathrm{~g}, 3.2 \mathrm{mmol})$ in dichloromethane $(200 \mathrm{ml})$ was treated with $p$-bromobenzyl trichloroacetimidate $(4.24 \mathrm{~g}, 12.8 \mathrm{mmol})$ in cyclohexane $(50 \mathrm{ml})$ and trifluoromethanesulfonic acid $(0.3 \mathrm{ml})$ at room temperature. After $26.5 \mathrm{~h}$, the reaction was terminated with pyridine $(6 \mathrm{ml})$. The mixture was washed with water $(100 \mathrm{ml})$, a saturated aqueous sodium hydrogen carbonate solution $(120 \mathrm{ml})$, and water $(100 \mathrm{ml})$. The organic layer was concentrated, and chromatographed on silica gel with $n$-hexane-ethyl acetate (3:1 in volume) as eluent. Yield was $2.9 \mathrm{~g}(64 \%)$. The product was crystallized from ethanol. $\mathrm{mp}, 98$ $99.5^{\circ} \mathrm{C}$. $[\alpha]_{\mathrm{D}}^{25}=+33.9^{\circ}$ (c 1.0, in chloroform).

${ }^{1} \mathrm{H}$ NMR data $\left(\mathrm{CDCl}_{3}, \mathrm{TMS}\right): 7.90$ and $7.60\left(2 \mathrm{~d}, J=8.5,4 \mathrm{H}\right.$, benzoyl- $\left.\mathrm{C}_{6} \mathrm{H}_{4}\right), 7.4$ $7.11\left(\mathrm{~m}, 8 \mathrm{H}\right.$, benzyl- $\left.\mathrm{C}_{6} \mathrm{H}_{4}\right), 5.52(\mathrm{~s}, 1 \mathrm{H}, \mathrm{H}-1)$, $5.14(\mathrm{~s}, 1 \mathrm{H}, \mathrm{H}-2), 4.85$ and $4.60(2 \mathrm{~d}, J=12.2$, $2 \mathrm{H}$, benzyl- $\mathrm{CH}_{2}$ ), 4.54 (d, $J=7.3,2 \mathrm{H}, \mathrm{H}-6_{\text {endo }}$ and $\mathrm{H}-5), 4.4\left(\mathrm{~d}, J=2.2,2 \mathrm{H}\right.$, benzyl- $\left.\mathrm{CH}_{2}\right)$, $3.87(\mathrm{~s}, 2 \mathrm{H}, \mathrm{H}-3$ and $\mathrm{H}-4)$, and $3.72(\mathrm{~d} \times \mathrm{d}$, $J \simeq 6.6$ and $5.6 \mathrm{~Hz}, 1 \mathrm{H}, \mathrm{H}-6_{\text {exo }}$ ).

${ }^{13} \mathrm{C} \mathrm{NMR}\left(\mathrm{CDCl}_{3}, \mathrm{TMS}\right): 164.4(\mathrm{C}=\mathrm{O})$, 136.7 and 136.4 ( para- $\mathrm{C}_{6} \mathrm{H}_{4}$ of benzyl), 131.7, 131.3, 131.2, 131.1, 129.1, 128.8, and 127.9, $\left(\mathrm{C}_{6} \mathrm{H}_{4}\right.$ of benzoyl and ortho- and meta- $\mathrm{C}_{6} \mathrm{H}_{4}$ of benzyl), 121.6, and 121.3 (ipso- $\mathrm{C}_{6} \mathrm{H}_{4}$ of benzyl), 99.2 (C-1), 74.2 (C-2), 72.8 (C-5), 72.7 (C-3), $71.7(\mathrm{C}-4), 70.5$ and 69.9 (benzyl- $\mathrm{CH}_{2}$ ), and 64.5 (C-6).

\section{Polymerization $^{3,4,10}$}

Each monomer was dried on calcium hydride in anhydrous dichloromethane in a polymerization vessel attached to a high 
vacuum system. Polymerization was carried out with phosphorus pentafluoride at $0^{\circ} \mathrm{C}$ to $-40^{\circ} \mathrm{C}$ and terminated with a cold mixture of methanol and pyridine. The product was chromatographed on silica gel with $n$-hexaneethyl acetate (2:1 in volume) as eluent to remove monomer. The eluate was concentrated and the residue was freeze-dried from benzene.

\section{Deprotection $^{3,4,10}$}

A solution of polymer $2(0.20 \mathrm{~g})$ in a mixture of toluene $(15 \mathrm{ml})$ and 1,2-dimethoxyethane $(5 \mathrm{ml})$ was added to $30 \mathrm{ml}$ of liquid ammonia at $-33^{\circ} \mathrm{C}$. Small pieces of freshly cut sodium metal were added to the mixture until the dark blue color of the solution persisted. A small amount of ammonium chloride and water $(15 \mathrm{ml})$ were successively added dropwise. The mixture was stirred overnight at room temperature to evaporate ammonia. The water layer was passed through a column of Amberlite IR-120 $\left(\mathrm{H}^{+}\right)$resin. The eluate was concentrated by a rotary evaporator and the product was reprecipitated into methanol. The methanol-insoluble fraction was freezedried from water to give a white hygroscopic powder.

\section{RESULTS AND DISCUSSION}

Synthesis of 1,6-Anhydro- $\beta$-D-galactopyranose Derivatives

1,6-Anhydro- $\beta$-D-galactopyranose ${ }^{6}$ was prepared from galactose and then the hydroxyl groups were protected regiospecifically with benzyl and benzoyl derivatives. Monomers 1a, $\mathbf{1 b}$, and 1c were prepared according to the previously reported reaction route ${ }^{5}$ which includes early benzylation with benzyl halides and subsequent benzoylation.

Monomer 1d was synthesized via the modified reaction route as shown in Scheme 2. The hydroxyl group in position 2 of 1,6-anhydro$3,4-O$-isopropylidene- $\beta$-D-galactopyranose was benzoylated at first, followed by removal of the isopropylidene group and subsequent benzylation of the resulting hydroxyl groups in positions 3 and 4 . This route involves no extra steps of protection and deprotection of the hydroxyl group in position 2. Instead, $p$-bromobenzyl trichloroacetimidate was employed as the benzylation reagent. The $p$ bromobenzylation was operated under mild acidic conditions to avoid the removal of the benzoyl group.

\section{Conformational Aspects of 1,6-Anhydro- $\beta$-D- galactopyranose Derivatives}

Compounds 1a-1d were obtained as crystals. The ${ }^{1} \mathrm{H}$ NMR spectral data were described in Experimental section. The assignments of some samples were based on the homo-decoupling technique. Although complete analysis has not been made, the chemical shifts and coupling constants were similar among the four compounds as follows. (1) Broad singlet signals of $\mathrm{H}-1$ and $\mathrm{H}-2$ appeared at 5.53 and $\sim 5.2 \mathrm{ppm}$, respectively. (2) The signals at $3.72 \mathrm{ppm}$ of $\mathrm{H}-6_{\text {exo }}$ were seemingly triplet, whose coupling constants were about 5 to $7 \mathrm{~Hz}$ due to $J_{\mathrm{H}-6 \mathrm{exo}, \mathrm{H}-5}$ and $J_{\mathrm{H}-6 \text { exo,H-6endo }}$. (3) One of the benzyl- $\mathrm{CH}_{2}$ signals were composed of an AB coupling system at 4.9 and $4.7 \mathrm{ppm}(J=12.1 \mathrm{~Hz})$. The former two characteristics are similar to those of skeletal 1,6-anhydro galactopyranose. ${ }^{11}$ There are no detectable differences in ring distortion which may be correlated with the polymerizability.

\section{Polymerization of 1,6-Anhydro- $\beta$-D-galactopy- ranose Derivatives}

Table I summarizes the results of polymerization of $\mathbf{1 a - 1 d}$.

Polymerizations of 1c using phosphorus pentafluoride as catalyst in dichloromethane proceeded at 0 and $-20^{\circ} \mathrm{C}$ to give methanol insoluble products at moderate yields (expt. IT-6 and IT-8). There appeared a single anomeric $\mathrm{C}-1$ carbon signal at $101.3 \mathrm{ppm}$, whose ${ }^{13} \mathrm{C}-{ }^{1} \mathrm{H}$ coupling constant $\left(J_{\mathrm{C}-1, \mathrm{H}-1}\right)$ was $163.0 \mathrm{~Hz}$ assignable to the coupling be- 
K. Kobayashi et al.

Table I. Polymerization of 1,6-anhydrogalactose derivatives $(\mathbf{1 a}-\mathbf{1 d})^{\mathbf{a}}$

\begin{tabular}{|c|c|c|c|c|c|c|c|c|c|c|}
\hline \multirow{2}{*}{$\begin{array}{c}\text { Exp. } \\
\text { no. }\end{array}$} & \multirow{2}{*}{ Monomer } & {$[\mathrm{M}]_{0}$} & \multirow{2}{*}{ Initiator $^{\mathrm{a}}$} & \multirow{2}{*}{ Solv. } & \multirow{2}{*}{$\frac{\text { Temp }}{{ }^{\circ} \mathrm{C}}$} & \multirow{2}{*}{$\frac{\text { Time }}{h}$} & \multirow{2}{*}{$\begin{array}{c}\text { Yield } \\
\%\end{array}$} & \multirow{2}{*}{$\begin{array}{c}M_{\mathrm{n}}{ }^{\mathrm{b}} \\
\times 10^{-3}\end{array}$} & \multirow{2}{*}{$\frac{[\alpha]_{\mathrm{D}}^{25 \mathrm{c}}}{\operatorname{deg}}$} & \multirow{2}{*}{$\frac{\beta \text {-Form }}{\mathrm{d}}$} \\
\hline & & $\operatorname{mol} 1^{-1}$ & & & & & & & & \\
\hline I-76 & 1a & 1.5 & PF5 & $\mathrm{CH}_{2} \mathrm{Cl}_{2}$ & 0 & 6 & 24 & 3.6 & +32 & $\sim 100$ \\
\hline I-77 & 1a & 1.5 & PF5 & $\mathrm{CH}_{2} \mathrm{Cl}_{2}$ & 0 & 48 & 66 & 2.6 & +27 & $\sim 100$ \\
\hline I-81 & $1 \mathbf{a}$ & 1.5 & PF5 & $\mathrm{CH}_{2} \mathrm{Cl}_{2}$ & -20 & 6 & 1 & - & - & \\
\hline I-89 & $1 \mathbf{a}$ & 1.5 & $\mathrm{BF}_{3} \mathrm{OEt}_{2}{ }^{\mathrm{g}}$ & $\mathrm{CH}_{2} \mathrm{Cl}_{2}$ & 0 & 48 & 30 & 1.8 & +38 & $\sim 100$ \\
\hline IT-22 & 1b & 1.2 & $\mathrm{PF}_{5}$ & $\mathrm{CH}_{2} \mathrm{Cl}_{2}$ & 0 & 48 & 16 & 1.6 & - & - \\
\hline IT-18 & 1b & e & $\mathrm{PF}_{5}$ & $\mathrm{CH}_{2} \mathrm{Cl}_{2}$ & -20 & 18 & 4 & 1.7 & +46 & - \\
\hline IT-6 & 1c & 1.2 & $\mathrm{PF}_{5}$ & $\mathrm{CH}_{2} \mathrm{Cl}_{2}$ & 0 & 6 & 50 & 3.8 & +45 & $\sim 100$ \\
\hline IT-8 & 1c & 1.2 & $\mathrm{PF}_{5}$ & $\mathrm{CH}_{2} \mathrm{Cl}_{2}$ & -20 & 48 & 35 & 2.5 & +27 & $\sim 100$ \\
\hline IT -9 & 1c & 1.2 & $\mathrm{PF}_{5}$ & $\mathrm{CH}_{2} \mathrm{Cl}_{2}$ & -40 & 48 & trace & 2.0 & - & \\
\hline IT-29 & 1c & $\mathbf{f}$ & $\mathrm{SbCl}_{5}{ }^{\mathrm{h}}$ & $\mathrm{CH}_{2} \mathrm{Cl}_{2}$ & 0 & 18 & 36 & 1.8 & +33 & $\sim 100$ \\
\hline IT-19 & 1c & 1.2 & $\mathrm{PF}_{5}$ & $\mathrm{CH}_{3} \mathrm{C}_{6} \mathrm{H}_{5}$ & 0 & 10 & 9 & 4.4 & - & $\sim 100$ \\
\hline \multirow[t]{2}{*}{ IT -20} & 1c & 1.2 & $\mathrm{PF}_{5}$ & $\mathrm{C}_{3} \mathrm{H}_{7} \mathrm{NO}_{2}$ & 0 & 6 & 56 & 4.6 & +38 & $\sim 100$ \\
\hline & & & & & & & 28 & 2.3 & +35 & - \\
\hline \multirow[t]{2}{*}{ IT-25 } & 1c & 1.2 & $\mathrm{PF}_{5}$ & $\mathrm{C}_{3} \mathrm{H}_{7} \mathrm{NO}_{2}$ & -20 & 12 & 36 & 3.6 & - & $\sim 100$ \\
\hline & & & & & & & 17 & 1.3 & - & - \\
\hline IT -23 & 1d & 1.2 & $\mathrm{PF}_{5}$ & $\mathrm{CH}_{2} \mathrm{Cl}_{2}$ & 0 & 6 & 56 & 3.1 & +36 & $<100$ \\
\hline IT-24 & 1d & 1.2 & $\mathrm{PF}_{5}$ & $\mathrm{CH}_{2} \mathrm{Cl}_{2}$ & -20 & 48 & 60 & 3.4 & +22 & $\sim 100$ \\
\hline IT-26 & 1d & 1.2 & $\mathrm{PF}_{5}$ & $\mathrm{CH}_{2} \mathrm{Cl}_{2}$ & -40 & 48 & 24 & 2.3 & +25 & $\sim 100$ \\
\hline
\end{tabular}

a Initiator, $\mathrm{PF}_{5}, 10 \mathrm{~mol} \%$.

b By GPC, polystyrene standard.

c In chloroform at $25^{\circ} \mathrm{C}$.

d By ${ }^{13} \mathrm{C}$ NMR spectroscopy.

e Monomer, $1.0 \mathrm{mmol} ; \mathrm{CH}_{2} \mathrm{Cl}_{2}, 0.55 \mathrm{ml}$.

f Monomer, $1.0 \mathrm{mmol} ; \mathrm{CH}_{2} \mathrm{Cl}_{2}, 0.50 \mathrm{ml}$.

g Initiator, $\mathrm{BF}_{3} \mathrm{OEt}_{2}, 30 \mathrm{~mol} \%$.

h Initiator, $\mathrm{SbCl}_{5}, 15 \mathrm{~mol} \%$.

tween the $\beta$ - anomeric carbon and axial hydrogen atom. ${ }^{12}$ The polymerization proceeded stereospecifically to give stereoregular polymers having $\beta$ - $(1 \rightarrow 6)$-linkage. Numberaverage molecular weights of the polymers estimated by GPC were $2500-3800$, which correspond to $\overline{D P_{n}}$ s of $4.1-6.3$. Deprotection of the benzyl and benzoyl groups of the polymers was performed using sodium in liquid ammonia to give the polysaccharide 3 quantitatively. The $\beta$ - $(1 \rightarrow 6)$-linked structure of the products was confirmed by comparing the ${ }^{13} \mathrm{C}$ NMR spectra with those of $\beta-(1 \rightarrow 6)$ galactopyranan oligosaccharides reported in the literature..$^{5,13}$

When boron trifluoride diethyl etherate and antimony pentachloride were used as initiators (expt. I-89 and IT-29), the products were of lower molecular weight.

Polymerizations of $1 \mathrm{c}$ with $\mathrm{PF}_{5}$ initiator in toluene and 1-nitropropane were compared with the polymerizations in dichloromethane. Polymerization was slow in toluene (expt. IT-19). Polymerization in 1-nitropropane gave products in rather high yields (expt. IT-20 and IT-25). However, there appeared two peaks in their GPC chromatograms, and two products with different structures were separated by silica gel chromatography. The higher molecularweight product was $\beta$ - $(1 \rightarrow 6)$-galactopyranan derivative which was similar to those obtained in dichloromethane and toluene. The lower molecular-weight product had a little different NMR resonances, and its chemical structure has not been identified.

Polymerization of monomer 1d proceeded 
at $0^{\circ} \mathrm{C},-20^{\circ} \mathrm{C}$, and even $-40^{\circ} \mathrm{C}$. Only the $\beta$-anomeric $\mathrm{C}$-1 carbon signal was observed at $100.8 \mathrm{ppm}$ for the product IT-24 and IT-26, although the $\alpha$-anomeric carbon signal was observed for the product (IT-23) obtained at $0^{\circ} \mathrm{C}$. The number-average molecular weights were in the range of $2300-3400\left(\overline{D P_{n}} \mathrm{~s}\right.$, $3.4-5.0)$.

Polymerization of $\mathbf{1 b}$ was slow, and the yield and molecular weight of the product were low, compared to those of $1 \mathbf{a}, \mathbf{1 c}$, and 1d. In the anomeric region of the ${ }^{13} \mathrm{C}$ NMR spectrum of the products (expt. IT-22 and IT-18) were observed two broad signals at 99.1 and $98.5 \mathrm{ppm}$. The polymer was of irregular structures.

\section{Polymerizability}

The polymerizability of 1 was lower than that of 1,6 -anhydro-2,3,4-tri- $O$-benzyl- $\beta$-Dgalactopyranose, ${ }^{6,14,15}$ the latter of which gave $(1 \rightarrow 6)-\alpha$-D-galactopyranan derivative with high $\alpha$-stereoregularity and high molecular weight. The polymerizabilities of the four monomers were in the order: $\mathbf{1 b}<\mathbf{1 a}<\mathbf{1 c}<\mathbf{1 d}$, as judged from the following comparison.

(1) Polymer yields at $0^{\circ} \mathrm{C}$ (expt. IT-22, I-77, IT-6, and IT-23).

(2) Apparent polymerizability as a function of temperature. Polymer could be obtained even at $-40^{\circ} \mathrm{C}$ from $1 d$ (expt. IT-26).

(3) High $\beta$-stereoregularity of the polymers obtained from 1a, 1c, and 1d, in contrast to the lack of stereoregularity of $\mathbf{1 b}$.

(4) For the products prepared from 1a were observed unassignable ${ }^{13} \mathrm{C}$ NMR signals at $20-45 \mathrm{ppm}$, which disappeared after deprotection. Some side reactions might occur at the sites of the protecting groups of $\mathbf{1 a}$. Such signals were not detected for the polymers 1c, 1d, and also for the deprotected polymers.

Introduction of bromine atom to the para positions of the benzyl and benzoyl groups increased the rate of polymerization, but did not increase the degree of polymerization.

\section{Reaction Mechanism}

Scheme 3 illustrates the proposed propagation mechanism, in which the neighboring benzoyloxy group in position 2 takes part in the steric control of the anomeric reaction center to produce the $\beta$ - $(1 \rightarrow 6)$-galactopyranan derivatives. The cyclic trialkyloxonium ion (I) ${ }^{14}$ is transiently formed at the growing terminal unit. It is immediately attacked by the carbonyl oxygen of the neighboring benzoyl substituent. As a result, the $\mathrm{C}-1$ configuration is inversed and a dioxacarbenium (dioxolenium or benzoyloxonium) ion (II) is formed. The conformation of the pyranose ring may be converted from ${ }^{1} \mathrm{C}_{4}$ to ${ }^{4} \mathrm{C}_{1}$ form (III). Then, the incoming monomer can attack the C-1 carbon of III exclusively from the

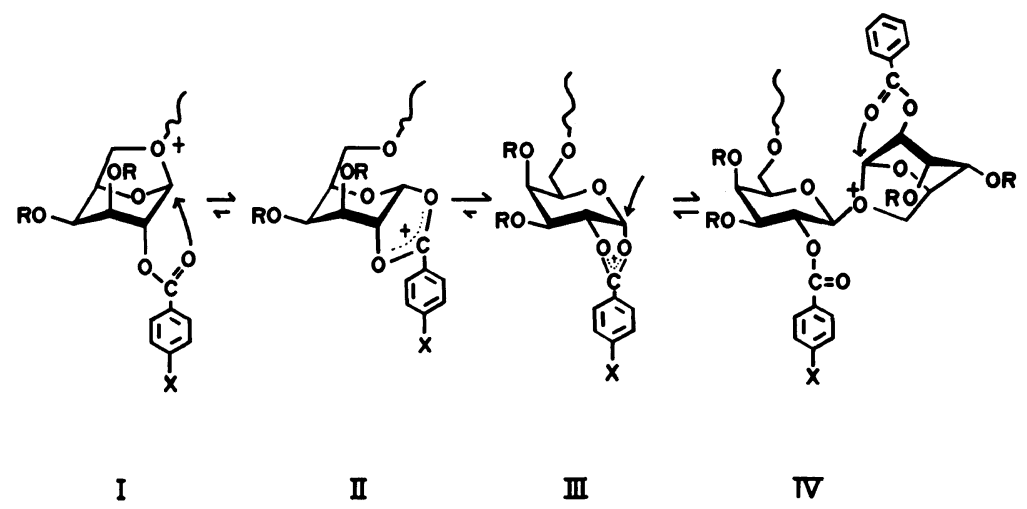

Scheme 3. Neighboring-group participation in formation of $(1 \rightarrow 6)-\beta$-linkage. 
opposite side of the dioxacarbenium ion, that is, the $\beta$-side of the pyranose ring. The $\mathrm{C}-1$ configuration is inversed again, and the trialkyloxonium ion (IV) is regenerated.

The ${ }^{1} \mathrm{C}_{4}$ conformation of monomers $\mathbf{1 a}-\mathbf{1 d}$ may be reasonably assumed on the basis of the above mentioned NMR data. ${ }^{11}$ The chair form conformations are also adopted for the intermediate species I-IV, although the possibility of other transitional conformations is not ruled out. The species I is directly converted to III in the previously proposed scheme. ${ }^{3,4}$ In Scheme 3, however, the species II has been placed between I and III to take into account some conformational change like ${ }^{1} \mathrm{C}_{4} \rightarrow{ }^{4} \mathrm{C}_{1}$. According to the examination of molecular models, the back-side attack of monomer to the reaction center of II seems to be inhibited owing to the steric hindrance.

The reactivities of the growing species toward monomers may be influenced by electronic nature of the substituents at the para position of the benzoyl and benzyl groups. It can be summarized from the following discussion that, on the whole, substituents with moderate electron-withdrawing characters must be introduced in order to enhance the overall reaction rate through I to IV.

In the step of I $\rightarrow$ II, the ester cabonyl group acts as a nucleophile, and hence an electrondonating substituent on the 2-O-benzoyl group will accelerate the formation of the species II. ${ }^{16}$ In the latter III $\rightarrow$ IV step, the same ester carbonyl group must act as a leaving group and, in this turn, an electron-withdrawing substituent is required. On the other hand, the electron-withdrawing substituent will lower the nucleophilicity of the acetal oxygen of anhydro ring and slow down the attack of the monomer toward the species III. Furthermore, the neighboring group participation $(\mathrm{I} \rightarrow$ II) also competes with the nucleophilic attack of the monomer toward the species I, the latter of which would result in the formation of $\alpha$-anomeric sequences. The chargebearing central carbon atoms of the benzoyl- oxonium ion (II and III) can also become a reaction centers of nucleophilic attack. ${ }^{17}$ The attack would yield quite different by-products instead of the normal ring-opening products.

Much slower polymerization of 1 than that of 1,6-anhydro-2,3,4-tri- $O$-benzyl- $\beta$-D-galactopyranose is rationalized by the following assumption. The dioxolenium ion III is thermodynamically more stable than the trialkyloxonium ion I and the rate-determining step is III $\rightarrow$ IV. As a result, the nucleophilic attack of the monomer to III becomes slow. The relative stability of species III is also responsible for the low degree of polymerization of the polymers 2 . In these respects, the neighboring group participation contributes to steric control but not to rate enhancement, that is, no anchimeric assistance.

It is also worth to note that a larger amount of Lewis acid $\mathrm{PF}_{5}$ as initiator was needed to polymerize the monomers 1 than 1,6-anhydro$2,3,4$-tri- $O$-benzyl- $\beta$-D-galactopyranose. Coordination of $\mathrm{PF}_{5}$ to basic oxygen atoms was increased in the presence of the ester functions and reduced by electron-withdrawing substituents on benzoyl and benzyl groups. ${ }^{18}$

As jugded from the lower polymerization rate and the lower stereoregularity of $\mathbf{1 b}$, $p$-nitrobenzoyl substituent was too strong an electron-withdrawing group. First, the nucleophilicity of the acetal oxygen of the monomer 1b was decreased. Second, the activation energy of the neighboring group participation $(\mathrm{I} \rightarrow \mathrm{II})$ might be elevated to allow the nucleophilic attack of the monomer toward the species I.

Bromine substituent of benzoyl group of 1d was more suitable to retain the $\beta$-anomeric configuration and increase the overall polymerization rate. The effects of bromo substituents of the benzyl groups in position 3 and 4 also must be considered. According to the comparison of $\mathbf{1 a}$ and $\mathbf{1 c}$, the bromo substituents increased the polymer yield but not the degree of polymerization. We assume that the initiation step ${ }^{19}$ is accelerated. 
1,6-Anhydro- $\beta$-D-galactopyranose derivative is known to possess lower ring-opening reactivity than other anhydro sugar skeletons. ${ }^{14}$ More highly reactive skeletal structures may be possible to give higher molecular weight polymers in higher yields.

Acknowledgments. The authors express their thanks to Professor Emeritus Hiroshi Sumitomo for his advice and to Mr. Sigeyuki Kitamura for carrying out the elemental analysis.

\section{REFERENCES}

1. C. P. J. Glaudemans, Molec. Immunol., 23, 917 (1986).

2. C. P. J. Glaudemans, Chem. Rev., 91, 25 (1991).

3. K. Kobayashi, H. Ichikawa, H. Sumitomo, and C. Schuerch, Macromolecules, 21, 542 (1988).

4. H. Ichikawa, K. Kobayashi, H. Sumitomo, and C. Schuerch, Carbohydr. Res., 179, 315 (1988).

5. V. K. Srivastava, S. J. Sondheimer, and C. Schuerch, Carbohydr. Res., 86, 203 (1980).
6. T. Uryu, H. Libert, J. Zachoval, and C. Schuerch, Macromolecules, 3, 345 (1970).

7. I. Fujimaki, Y. Ichikawa, and H. Kuzuhara, Carbohydr. Res., 101, 148 (1982).

8. T. Iversen and D. R. Bundle, J. Chem. Soc., Chem. Commun., 1240 (1981).

9. H. Wessel, T. Iversen, and D. R. Bundle, J. Chem. Soc., Perkin Trans. 1, 2247 (1985).

10. C. Schuerch and T. Uryu, Macromol. Synth., 4, 151 (1972).

11. M. Budesinsky, T. Trnka, and M. Cerny, Collect. Czechoslov. Chem. Commun., 44, 1949 (1979).

12. K. Bock and C. Pederson, J. Chem. Soc., Perkin Trans. 2, 293 (1974).

13. P. Kovac, Carbohydr. Res., 153, 237 (1986).

14. C. Schuerch, Adv. Carbohydr. Chem. Biochem., 39, 157 (1981).

15. T. Uryu and C. Schuerch, Macromolecules, 4, 342 (1971).

16. U. Pindur, J. Muller, G. Flo, and H. Witzel, Chem. Soc. Rev., 16, 75 (1987).

17. H. Paulsen, Adv. Carbohydr. Chem. Biochem., 26, 127 (1971).

18. H. Ito and C. Schuerch, J. Polym. Sci., Polym. Lett. Ed., 19, 43 (1981)

19. T. Uryu, K. Ito, K. Kobayashi, and K. Matsuzaki, Makromol. Chem., 180, 1509 (1979). 